Academic Entrepreneurship for Medical and Health Scientists • Academic Entrepreneurship for Medical and Health Sciences

\title{
Startup Company \\ Formation and \\ Management
}

Jenny Cai ${ }^{1}$, Ben Doranz ${ }^{2}$

${ }^{1}$ Bristol Myers Squibb, ${ }^{2}$ MBA, PhD; Integral Molecular, Inc.

Published on: Sep 27, 2019

DOI: 10.21428/b2e239dc.a150c98d

License: Creative Commons Attribution-NonCommercial-NoDerivatives 4.0 International

License (CC-BY-NC-ND 4.0). 


\section{Topic Relevance by Timeline}

\section{Summary}

- Startups are often built with a small team of talented and highly motivated individuals who are passionate about the company.

- The environment of a startup is often demanding, with time-sensitive projects and limited resources.

- The three common types of business entities for a startup are an LLC, an S corp, and a C corp, and each offers its own advantages based on the startup's trajectory and goals for growth.

- Delaware's corporate laws and statutes are pro-business, and many companies choose to incorporate in Delaware.

- State law requires that corporations hold shareholder and board of directors meetings to vote on crucial company decisions and document them officially in meeting minutes.

- Seeking counsel from a tax advisor and a legal advisor early on can potentially contribute to a startup's financial prospects both in the short and the long term.

\section{Introduction}

Forming a startup requires having realistic expectations for the company and the employees. Startups often begin with limited resources, and so each task completed and decision executed should be carefully planned out. The purpose of this chapter is to review key decisions and steps in the formation process of a startup. For example, one of the important decisions to make with a startup is the type of corporation to file for and which state to file in. We then move on to describe key meetings and documents necessary for startup operations and discuss resources that can provide advice and counsel.

\section{Expectations for a Startup}

The environment for a startup is often demanding and challenging. Projects are timesensitive and there are limited resources to operate. With a small team, each team 
member will often be given independence to complete tasks. This is generally a rewarding experience because there is an opportunity to learn new skills and lead projects. Working in small teams can contribute to a close-knit environment that is dedicated and focused on completing the task and meeting deadlines (see the chapter “Building_a Successful Startup Team”).

Most startups offer flexible hours and schedules, but team members are expected to meet deadlines for time-sensitive projects. There is often less structure, and much of the work is driven by self-motivation and initiative to meet business milestones. Initial company seed funding is often unpredictable and typically can occur in six-month to two-year periods, with the subsequent period dependent upon obtaining additional financial support. Often, each expense is tracked carefully to maintain working cash flow. Effective management of capital is a sign of maturity for a startup. Compensation for employees often takes the form of salary and benefits that are between the range of academic and industry setting. Additionally, employees in startups are often granted equity to tie in their performance to the growth of the company.

\section{Types of Startup Companies}

Registering a startup as a corporation lends more credibility to the business and provides more legal protection. A limited liability company (LLC) is a very common corporate structure for a startup because of the benefits and ease of registering. The benefits of registering a young company as an LLC include avoiding double taxation, reducing restrictions for maintenance and making changes to the company, protections on personal assets from lawsuits, and a lowered cost to file. Startups may often begin as an LLC and, after expansion and growth, convert to a $\mathrm{C}$ or $\mathrm{S}$ corporation to attract investors with equity/stock options. Alternatively, startups that do not plan to issue company stock or raise funding may choose to remain as an LLC (Boitnott).

S corporations are often appropriate for startups that have one class of stock and fewer than 100 shareholders. The shareholders are specified as individuals, certain trusts, and estates, with corporations and partnerships excluded. In addition to limited liability, the main benefit, compared to a $\mathrm{C}$ corporation, is pass-through taxation where shareholders file taxes annually and report their losses and profits individually ("Business Structures"). If the company plans to remain a small business, then the S corp model may work best for its needs. Unlike with an LLC and a C corporation, registering for an S corporation is for U.S. citizens and legal residents only ("What Is an LLC? Form a Limited Liability_Company"). 
C corporations are one of the most common corporation structures in the U.S. and allow for high growth potential. The limitations in the number of shareholders and sales of stock in an S corporation do not apply to C corporations. A C corporation can attract major investors like venture capitalists with unlimited sale of stocks and high growth potential. When the startup reaches more than 500 shareholders and/or more than $\$ 10$ million in assets, it is required to register with the Securities and Exchange Commission (SEC). One of the major disadvantages is double taxation, which occurs at the company level as well as individually with shareholders' dividends. However, most startups tend to reinvest the dividends, and so this second taxation does not apply often. Taxes are filed quarterly.

The public benefit corporation is an option if the startup's purpose contributes to a general public benefit. The startup can build or invest in a company that operates in a socially and/or environmentally conscious manner. Registering as a benefit corporation requires two-thirds of the shareholders' votes and can be done when filing for articles of incorporation or making an amendment to change to this status. The application is filed with the Bureau of Corporations and Charitable Organizations. The requirements of a public benefit corporation include filing an annual benefits report to the State Department, mainly detailing the general public benefit created during the year and the compensation of each company director ("Pennsylvania Benefit Corporation").

When the startup is considering which state to incorporate in, Delaware stands out as having advantages that have favored businesses since the early 1900s. More than half of Fortune 500 companies are incorporated in Delaware. One of the main reasons is the dynamic design of Delaware's General Corporation Law, which has regularly updated provisions to ensure flexibility in corporate structure; this is upheld in their Court of Chancery, a court established just for corporate cases. Furthermore, corporations that do not conduct business within Delaware are not liable for corporate taxes. In Delaware, a quorum for shareholder meetings is met when one-third of the voting shareholders are present (Black).

\section{Understanding Goals and Resources}

Creating a startup requires keeping the company goals in mind when thinking ahead and planning for sequential tasks to complete. One of the first steps in building a solid foundation for the startup is to establish the roles, decision-makers, rules for leaving the company, and personal contributions (such as funds and time commitment) of each founder and senior management. This is specified clearly in a legal document, the founders' agreement, which is typically drawn up prior to incorporating the company. 
To prepare a founders' agreement, it can be helpful to have a clear understanding of each founder's perspective. A useful tool in this regard is an agreement questionnaire; a detailed example of one, provided courtesy of Fox Rothschild LLP, is included at the end of this chapter.

\begin{tabular}{|l|l|l|l|}
\hline & C Corp & S Corp & LLC \\
\hline Limited Liability & YES & YES & YES \\
\hline Unlimited Owners/Shareholders & YES & NO & YES \\
\hline Owners must be U.S. citizens or residents & NO & YES & NO \\
\hline Startup can be owned by another business & YES & NO & YES \\
\hline Can issue equity in the form of stocks & YES & YES & NO \\
\hline Owners can report business profit and loss on their personal tax returns & NO & YES & YES \\
\hline Owners can split profit and loss with the business for a lower overall tax rate & YES & NO & NO \\
\hline Annual meetings or record meeting minutes & YES & YES & NO \\
\hline
\end{tabular}

Figure 1

Comparison of Types of Corporations: C corp, S corp, and LLC.

\section{Company Governance}

Proper company governance is the foundation for the success of a startup and is highly influenced by the stakeholders' interests. Typically, the stakeholders in a company include the shareholders, employees, consumers, suppliers, government, and community. A company runs most smoothly when there is a balance of the stakeholders' interests. S corps and C corps are required to hold annual or "regular" shareholder meetings to discuss and vote on agenda items. Having an odd number of board members is an advantage to avoid ties when counting votes for a decision. Examples of common items on the agenda include adding/removing directors, mergers, sale of assets, and voting on shareholder initiatives. Board members can call for a special shareholders' meeting to discuss time-sensitive resolutions, such as for acquisitions and conversions. 
A board of directors is established at the start of a company, as required by law. Typically, the board of directors consists of the founder(s) and the CEO of the startup, who make all key decisions regarding raising capital, potential acquisitions, staffing upper management, assessing risks, and making strategic transactions. As the company grows, board members are added and removed. This often occurs when the startup enters rounds of funding and, in exchange for capital, the investor requires a specified number of board seats. Board of directors meetings occur regularly to discuss and implement company-wide policies, execute objectives, approve annual budgets, and evaluate company performance. Minutes for the shareholder and board meetings are the official documentation of the agenda items discussed and decisions made during the meeting. The content of the minutes are often kept light and brief, with a list of the attendees, date, time, and place of the meeting.

\section{Legal Contracts and Agreements}

Creating a strong legal structure is crucial to protecting the startup. Formulating legal contracts and agreements ahead of time may prevent costly legal battles for the company down the line. When the startup chooses to incorporate, the legal document certifying the business is the articles of incorporation, and it provides limited liability for business debts and obligations. Another important document is the intellectual property (IP) assignment agreement, and the two types of this are the technology assignment agreement and the invention assignment agreement. The technology assignment agreement assigns the IP rights to the owners prior to the formation of the company (see the chapter "Intellectual Property: Ownership and Protection in a University Setting"). The invention assignment agreement declares that progress made toward developing the IP is owned by the company. The founders' (or operations) agreement, mentioned previously, defines the relationship of the cofounders and establishes guidelines for resolving disputes among the founders (Faustman).

The nondisclosure agreement (NDA) is necessary to safeguard the IP and maintain the confidentiality of company ideas and property. The NDA is commonly used when discussing non-public information about the company with any outside party. The NDA specifies what information is confidential, how confidentiality should be handled, the owner of the information, and the time frame of maintaining confidentiality. As part of company governance, the CEO and founders should create a clearly written employee contract and offer letter for hiring, to set clear expectations of roles, compensation, and company policies with new employees. When attracting investors to the company, the shareholders agreement should be drawn to specify the rights of each shareholder, 
and when to exercise those rights. Examples of shareholder rights to define include the authority of the shareholder as a decision-maker, when shares can be transferred, the redemption of shares, and the right of first refusal. When drawing up agreements and contracts, consult with a trusted legal advisor to ensure all bases are covered (Faustman).

\section{Other Key Regulatory Requirements}

When starting a company, one of the first steps is to obtain an employer identification number (EIN) with the IRS, for tax administration. This application process can be completed online, by fax, or by mail for free. To apply, the applicant must have a valid tax identification number such as a social security number, employer identification number, or individual taxpayer identification number. Most banks require an EIN for a startup before creating a business account ("Apply for an Employer Identification Number EIN Online").

\section{Obtaining Expert Counsel}

A tax advisor such as an experienced accountant can help manage the finances and taxes. It is important to hire an accountant who has experience in working with small businesses since some startups have complex and specific accounting needs. In addition to maintaining the finances for the company, a seasoned accountant can serve as a trusted advisor to help plan for the company's growth and assess financial risks. Referrals within one's professional network are often a solid way to find a trusted accountant.

A legal advisor is essential to counsel the startup in setting up a corporation (LLC vs. S or C corp) and in protecting the integrity of the company. Most contract-based legal advisors are lawyers who focus their careers on corporate law. They are tasked with negotiating and drafting contracts of various types for the startup, such as consultant contracts and collaboration agreements. They also ensure that the startup is operating in compliance with corporate law. Referrals within one's network are a good way to find a suitable legal advisor. A university technology transfer office (TTO), business school, or entrepreneurship/innovation center are also potential sources for contract lawyer referrals (see the chapter "Working with the University_Technology Transfer Office"). Furthermore, if there is an affiliated university law school, it can provide a professional network and a referral for a corporate lawyer who suits the startup's needs. In some cases, they may also offer classes, student groups, legal clinics, or 
other resources ("What Is a Legal Advisor?"). An accelerator or incubator may also have a network for referrals (see the chapter "Accelerators and Incubators").

A unique benefit of working with tax advisors or legal advisors with experience in the startup area is that they can be a valuable source for referrals to other consultants or experts in related areas, such as manufacturing, sales, management, etc.

\section{Conclusion}

Establishing a startup company can be a very rewarding venture if it is started with the right expectations and guidance. Startups are often fast-paced and project-/product-focused. Teams work both closely together and independently to deliver on deadlines. In these early stages of a startup, one of the first few decisions to make is which type of corporation to register as. The three most common types, LLC, S corp, and C corp, each have their own advantages and disadvantages. A legal advisor can counsel on which type best fits the milestones and growth of the company. Another important aspect of startup formation is company governance and the careful selection of each member of the board of directors. The key decisions made in the shareholder and board of directors meetings shape the company's future for better or worse.

\section{Practical Guides/Worksheets}

Supplement 1: Agreement Questionnaire, adapted from a questionnaire provided courtesy of Fox Rothschild LLP.

\section{Resources}

Information about LLC, $\underline{\mathrm{S} \text { corp}}$, and C corp from the IRS website.

Differentiating the advantages and disadvantages of LLC, $\mathrm{S}$ corp, and C corp.

Article from the government of Delaware on the benefits of incorporating in Delaware. EIN application instructions from the IRS website. 
The contents of this chapter represent the opinions of the chapter authors and editors. The contents should not be construed as legal advice. The contents do not necessarily represent the official views of any affiliated organizations, partner organizations, or sponsors. For programs or organizations mentioned in this chapter, the authors encourage the reader to directly contact the relevant organization for additional information.

\section{Citations}

1. Boitnott, John. "5 Reasons Why an LLC Is the Right Structure for Your Startup." Inc., 20 Feb. 2015, https://www.inc.com/john-boitnott/5-reasons-why-an-llc-is-theright-structure-for-your-startup.html. $\_$

2. "Business Structures." Internal Revenue Service, https://www.irs.gov/businesses/small-businesses-self-employed/business-structures. Accessed 13 Aug. 2019.

3. "What Is an LLC? Form a Limited Liability Company." Incorporate.com, https://www.incorporate.com/starting-a-business/limited-liability-company $L$. Accessed 13 Aug. 2019.

4. "Pennsylvania Benefit Corporation." Pennsylvania Department of State, https://www.dos.pa.gov/BusinessCharities/Business/Resources/Pages/PennsylvaniaBenefit-Corporation.aspx. Accessed 13 Aug. 2019.

5. Black, Lewis S., Jr. "Why Corporations Choose Delaware." State of Delaware / The Official Site for the First State, 2007, https://corpfiles.delaware.gov/whycorporations web.pdf. $\triangleq$

6. Faustman, Matthew. "The Top 7 Legal Documents for Every Startup." Entrepreneur, 11 Jan. 2016, https://www.entrepreneur.com/article/253997..

7. "Apply for an Employer Identification Number (EIN) Online." Internal Revenue Service, 10 July 2019, https://www.irs.gov/businesses/small-businesses-selfemployed/apply-for-an-employer-identification-number-ein-online...

8. "What Is a Legal Advisor?" JobHero, https://www.jobhero.com/what-is-a-legaladvisor/. Accessed 13 Aug. 2019. 